\title{
A METÁFORA DAS ORGANIZAÇÕES VISTAS COMO CULTURAS A PARTIR DA PERSPECTIVA DE MORGAN E SUA BASE TEÓRICA
}

\section{THE METAPHOR OF ORGANIZATIONS SEEN AS CULTURES FROM THE PERSPECTIVE OF MORGAN AND ITS THEORETICAL BASIS}

\author{
Eduardo Robini da Silva \\ Doutorando em Administração - PPGA UCS Universidade de Caxias do Sul \\ Caxias do Sul, RS, Brasil \\ E-mail: eduardorobini@gmail.com \\ Juliana Furlan \\ Mestranda em Administração - PPGA UCS Universidade de Caxias do Sul \\ Caxias do Sul, RS, Brasil \\ E-mail: juli.furlan2@gmail.com \\ Thiago Finimundi \\ Mestre em Administração - PPGA UCS Universidade de Caxias do Sul \\ Caxias do Sul, RS, Brasil \\ E-mail: tafinimundi@gmail.com \\ Adrieli Alves Pereira Radaeli \\ Doutoranda em Administração - PPGA UCS Universidade de Caxias do Sul \\ Caxias do Sul, RS, Brasil \\ E-mail: adrieli.radaelli@gmail.com \\ Eric Charles Henri Dorion \\ Professor em Administração - PPGA UCS Universidade de Caxias do Sul \\ Caxias do Sul, RS, Brasil \\ E-mail: echdorion@gmail.com
}

\section{RESUMO}

A cultura no ambiente organizacional influencia diretamente o comportamento dos colaboradores. A metáfora, por conseguinte, auxilia na reflexão de muitos aspectos deste ambiente, dentre elas a estratégia, a estrutura e o tipo de liderança desta organização. Dado esse contexto, o objetivo da pesquisa foi analisar a produção de artigos acerca da evolução dos estudos sobre as organizações vistas como culturas do autor Gareth Morgan e sua base teórica, encontrada na obra "Imagens da Organização", de 2002. A pesquisa utilizou como método uma revisão sistemática da literatura, com abordagem qualitativa, objetivo exploratório e descritivo. A Base de Dados para realizar a pesquisa foi a Scopus, foram selecionados todos os anos até 2016. Como resultado da pesquisa, foram encontrados 55 artigos, os critérios de exclusão foram os artigos "not open file" e o critério de inclusão abrange os artigos que considerassem as organizações como fenômenos culturais, os quais tinham a cultura organizacional como objeto principal de investigação; e a criação da realidade organizacional baseado nesse enfoque. O que resultou, a partir dos critérios, na análise aprofundada de sete artigos. A principal contribuição dos trabalhos selecionados foi que os estilos de liderança são fundamentais para a perpetuação da cultura organizacional e esta, por sua vez, serve de suporte para a criação de conhecimento, criatividade e inovação. A contribuição deste estudo conduz à ideia das organizações como manifestações do contexto social onde estão inseridas, sendo que as mesmas só podem existir em sociedades onde os membros compartilhem das características de um sistema social, de relações. Como contribuição teórica, o trabalho propõe uma atualização da metáfora das organizações vistas como culturas, dentro de um contexto atual, analisando a evolução dos estudos que se referenciaram a Gareth Morgan e sua base teórica.

Palavras-chave: Cultura Organizacional. Gareth Morgan. Revisão Sistemática. Metáfora.

Data de submissão: 14 de abril de 2017.

\section{ABSTRACT}

Culture in the organizational environment directly influences employee behavior. The metaphor, therefore, helps in the understanding of many aspects of this environment, among them organization's strategy, structure and leadership. Given this context, the objective of this research was to analyze the production of articles on the evolution of the studies on the organizations as cultures from Gareth Morgan's "Images of the Organization", of 2002 and its theoretical basis. A systematic review of the literature was carried out, with qualitative approach, and exploratory and descriptive objective. The database to perform the research was Scopus, with selection of every year until 2016. As a result of the research, 55 articles were found. Exclusion criteria were "not open file" articles and the inclusion criteria covers articles in which organizations were considered as cultural phenomena, which had the organizational culture as the main object of investigation; and the creation of organizational reality based on this approach. This resulted, from the criteria, in the in-depth analysis of seven articles. The main contribution from selected articles is that leadership styles are fundamental to the perpetuation of organizational culture and this, in turn, serves as support for the creation of knowledge, creativity and innovation. The contribution of this study leads to the idea of organizations as manifestations of the social context where they are inserted, as they can only exist in societies where members share the characteristics of a social system of relationships. As a theoretical contribution, this paper proposes an update of the metaphor of the organizations seen from within the context, analyzing the evolution of the studies that referred to Gareth Morgan and its theoretical basis.

Keywords: Organizational Culture. Gareth Morgan. Systematic Review. Metaphor. 


\section{INTRODUÇÃO}

O avanço da pesquisa no campo da cultura organizacional com a obra de Morgan (2002) ganha relevância a partir do impacto de seu trabalho na transformação do paradigma de interpretação das organizações em contextos distintos daqueles tradicionalmente observados. Cabe, todavia, ressaltar que este trabalho não assume como pioneiro o trabalho de Morgan (2002), porém torna-se relevante no sentido de convergir distintas abordagens. Por este motivo, optou-se por analisar a base conceitual proposta por Morgan, para então avaliar os resultados de seu trabalho após mais de uma década de sua publicação.

A cultura organizacional apoia-se nos hábitos, práticas, símbolos, comportamentos, valores éticos e morais, ademais de crenças, princípios, políticas, sistemas e clima de uma organização. Ela é resultado das negociações de significados, valores e propriedades dos integrantes de uma organização com o seu contexto. Logo, caracteriza a mentalidade que prevalece no contexto organizacional. A comunicação é essencial para esse processo, pois é coeficiente na construção de sentido compartilhado na organização, preservando assim seus valores e garantindo sua perpetuação.

Assim, este trabalho busca analisar a evolução das pesquisas sobre as organizações vistas como culturas com base nos estudos de Gareth Morgan e a construção teórica de seu livro "Imagens da Organização", datado de 2002. Para responder a esse objetivo, a pesquisa utilizou como método uma revisão sistemática da literatura, com abordagem qualitativa e objetivo exploratório e descritivo. Para o estudo, foram efetuadas pesquisas na base de dados Scopus, na qual foram pesquisados apenas "artigos", até o ano de 2016. A estratégia de busca deu-se em três etapas, as quais serão detalhadas na metodologia. Como resultado da pesquisa, obteve-se 55 artigos, dos quais, após os critérios de exclusão e inclusão, resultou em sete artigos, que foram analisados em profundidade.

O artigo está estruturado em introdução, seguida do referencial teórico, onde será explorada a base teórica de Morgan (2002) e, posterior a isso, será abordada a metodologia do artigo. Por fim, será abordada a análise e discussão dos resultados, seguida da conclusão e a proposta de metáfora sugerida pelos autores.

\section{REFERENCIAL TEÓRICO}

Nesta seção, serão apresentadas as organizações vistas como culturas de acordo com o exposto pelo autor Gareth Morgan em sua obra Imagens da Organização (2002). Para o autor, metaforicamente partese da assunção que uma cultura é uma realidade social, construída como resultado de um processo complexo, que habilita aos envolvidos ver e interpretar eventos, ações, objetos, declarações ou situações específicas de maneiras distintas (MORGAN, 2002). Para suportar esta metáfora, Morgan (2002) utilizou como base teórica para sustentar seus pilares autores como: Presthus (1962), o qual aborda as organizações como sociedades, Garfinkel (1967), que traz a ideia do senso comum com as práticas sociais, e por fim, Weick (1979), o qual enfatiza sobre as organizações orientadas como processo. 


\section{A SOCIEDADE ORGANIZACIONAL - A BASE TEÓRICA DE MORGAN}

Para Presthus (1962), fazer parte de uma sociedade organizacional vai habilitar seus membros a executarem práticas culturais complexas. O estudo destas práticas sociais complexas empregadas na construção do mundo social estável, como declarações e ações cotidianas, é chamado etnometodologia (GARFINKEL, 1967).

Dessa forma, o processo da cultura não pode ser imposto, uma vez que se desenvolve no decorrer da interação social (MORGAN, 2002). Por meio de uma análise interdisciplinar de grandes organizações e sua influência sobre os indivíduos que nelas trabalham, Presthus (1962) definiu organizações como sociedades em miniatura, onde os valores dominantes da sociedade são aplicados e buscados em um contexto estruturado e espacialmente restrito. Conceitualmente, a sua análise opera em três níveis distintos, mas interligados, quais sejam: (i) a sociedade como um todo; (ii) a grande organização racional e; (iii) o indivíduo (PRESTHUS, 1962).

Sendo assim, a organização como um fenômeno cultural vai se manifestar diferentemente de acordo com o nível de desenvolvimento da sociedade onde está inserida (MORGAN, 2002). Dessa forma, para Morgan (2002), o nível de desenvolvimento social vai implicar na cultura corporativa, que são os padrões de interação (liderança), valores, rituais, ideologias e crenças deste fenômeno cultural. $\mathrm{O}$ autor ainda sustenta que, em função deste contexto, é necessário que se considere a cultura da sociedade (micro) ao invés da cultura de sociedade (macro).

Garfinkel (1967) trata dos padrões de interação, valores, rituais e ideologias como temas de estudo empírico e, prestando atenção às atividades mais comuns da vida diária, trata-as como fenômenos com sua própria verdade. Um interesse empírico central do trabalho de Garfinkel (1967) é a nuance do conhecimento comum - o conhecimento de senso comum - que as pessoas usam para navegar suas vidas diárias e tarefas. Em consonância a este senso comum está o trabalho de Weick (1979), que escreve sobre a organização orientada ao processo, ao invés da organização orientada à estrutura. Nesse caso, a comunicação é fundamental para o processo de organização, uma vez que é um grande fator na construção de sentido compartilhado (WEICK, 1979).

Para Weick (1979), o processo de criação de sentido é uma tentativa de reduzir a ambiguidade ou múltiplos significados na informação utilizada pelas pessoas dentro da organização. Isso se dá uma vez que a organização é interpretada por Weick (1979) como um sistema aberto, recebendo informação de seu ambiente e tentando dar sentido a essas informações, usando o que foi aprendido. Dessa forma, as organizações evoluem a partir do sentido que criam de si e seu ambiente (WEICK, 1979).

Uma vez que a criação deste sentido é compartilhada e condensada, pode haver dissonância, que se manifesta na forma de coalizões ou contraculturas em oposição aos valores organizacionais adotados pelos que detêm o controle formal. Segundo Morgan (2002), a politicagem, por meio da qual membros de uma organização, algumas vezes, progridem em suas carreiras ou defendem interesses específicos, pode resultar no desenvolvimento destas coalizões, então sustentadas por conjuntos de valores específicos. Whyte (1948) busca entender a tensão entre os sistemas formais e informais dentro das organizações examinando as hierarquias e linhas de comando. Para ele, há pessoas que necessitam de uma elevada taxa de interação 
e atividade social além de mudanças físicas nas atividades, a fim de ser felizes no seu trabalho (WEICK, 1979).

\section{Organizações vistas como culturas - segundo Gareth Morgan}

Para Morgan (2002), a principal contribuição do estudo das organizações sob o prisma da cultura, é a compreensão deste aspecto na construção e análise de uma organização. Assim, se considera o peso dos valores, ideias, crenças, rituais e outros padrões de sentido comum que persistem e se identificam aos sistemas a que se referem. Desta forma, a cultura de uma organização é a imagem representativa de seu ambiente constitutivo, ou seja, é o resultado de tradições e costumes consolidados na cultura nacional ou regional (MORGAN, 2002).

O autor constrói sua argumentação sobre as organizações como realidades sociais a partir do pressuposto de que as teorias organizacionais se fundamentam em metáforas. Estas imagens implícitas motivam a forma como vemos, entendemos e lidamos com a realidade de forma assimétrica, pois aquilo com o que interagimos cria um espectro de relações que desconsideramos (MORGAN, 2002). Sendo assim, não há uma única teoria capaz de explicar de forma completa a realidade construída a partir da manifestação cultural, ainda que seja válido o emprego desta metáfora ao entendimento de aspectos sociais das organizações (MORGAN, 2002).

A realidade social se manifesta como uma cultura, resultado de um processo complexo de construção e criação de sentido coletivo, que habilita aos envolvidos ver e interpretar eventos, ações, objetos, declarações ou situações específicas de maneiras distintas (MORGAN, 2002). A construção desta realidade social, para Presthus (1962), fundamenta-se na estrutura burocrática e de valores sociais dos membros das grandes organizações nas sociedades. Mais especificamente, a partir das tentativas de definir os padrões de pertencimento individuais que ocorrem no meio burocrático (PRESTHUS, 1962). Fazer parte desta sociedade organizacional é o que habilita seus membros a executarem as práticas culturais complexas que constituem o processo de construção da realidade social (PRESTHUS, 1962).

Morgan (2002) aponta que a cultura corporativa, neste contexto, se fundamenta e reflete os valores e crenças que caracterizam as diferentes culturas onde estão inseridas as organizações. Desta forma, embora se adote alguns valores inovadores, a organização continua dependente de um tipo de cultura que a caracteriza, ou seja, elas crescem em um quadro cultural definido (MORGAN, 2002). Projetando a organização como uma cultura, então, se oferece uma alternativa aos modos de desempenho individual e coletivo alterando modos de ver, visões e imagens, crenças e significados comuns que servem de apoio para a organização (MORGAN, 2002).

O estudo destas práticas sociais complexas empregadas na construção do mundo social estável, como declarações e ações cotidianas, é chamado etnometodologia (GARFINKEL, 1967). Para Garfinkel $(1967 ; 1988)$ a etnometodologia representa um esforço para entender os métodos através dos quais os membros de uma sociedade constroem as interfaces da vida cotidiana de forma real, concreta, e não hipotética. Há na sociedade uma ordem autogerada por tais atividades concretas, uma ordem cuja apreciação não depende nem da descrição prévia, nem da generalização empírica, ou especificação formal de elementos variáveis e suas relações analíticas (GARFINKEL, 1967; 1988). 
O trabalho de Presthus (1962) trata do contexto, onde a estrutura burocrática constitui um campo regular, ou uma sociedade em miniatura, composto de três sistemas distintos: autoridade, status, e pequenos grupos. Organizações são, portanto, sistemas, um complexo de pequenos grupos em interação que têm influência sobre o comportamento semelhante (PRESTHUS, 1962; MORGAN, 2002). Tais grupos imprimem valores organizacionais em seus membros; recompensam o cumprimento e punem aqueles que resistem às suas demandas. Em muitos casos, os valores do grupo contribuem para os objetivos manifestos da organização. Em outros, entram em conflito com eles. Mas em todos os casos, pequenos grupos têm uma função socializadora generalizada. Em suma, os três sistemas de autoridade, status e pequenos grupos proporcionam as principais condições de participação social (PRESTHUS, 1962).

Para o indivíduo, a cultura representa os padrões de sua existência e, qualquer pessoa que viole, fora do quadro de representação comum, tais padrões, é interpretada como oposição. A cultura é essencialmente um conjunto de códigos e regras não escritas que promove e assegura a coesão e a reunião pacífica de vários indivíduos (MORGAN, 2002). A cultura da empresa, para Morgan (2002), é o conjunto de comportamentos individuais que definem a identidade de uma organização. O padrão desempenha um grande papel na motivação dos empregados ou desinteresse, e é, em grande parte, influenciado pelo contexto cultural em que a empresa opera (MORGAN, 2002).

Dessa forma, o campo estruturado de Presthus (1962) compreende os estímulos que facilitam a percepção e aprendizado, fornecendo o feedback que orienta e limita as escolhas individuais. Garfinkel (1967), todavia, preocupa-se com as ações que compõem o processo de interação dentro deste contexto. Para Garfinkel (1988), como função da realização de suas atividades diárias, as pessoas omitem o sentido daquilo que estão realmente falando. As propriedades aceitas do discurso comum compreendem a expectativa de que as pessoas entendam a imprecisão específica de referências, em um sentido retrospectivo-prospectivo das ocorrências, esperando por seus resultados como forma de antever o que foi feito (GARFINKEL, 1967). Tais ações fornecem uma base de características observáveis, mas despercebidas, do discurso comum, pelo qual os enunciados reais são reconhecidos como eventos de interesse comum (GARFINKEL, 1967; 1988).

Em consonância a este senso comum está o trabalho de Weick (1979), que escreve sobre a organização orientada ao processo, ao invés da organização orientada à estrutura. De acordo com Weick (1979) as organizações são um processo em constante mudança, haja vista que as pessoas estão conscientes dos relacionamentos, e os membros de uma organização não podem separar-se como indivíduos. Assim, o indivíduo como membro da organização é consciente do significado que impõem a si próprio, aos outros atores e ao ambiente (WEICK, 1979).

Weick (1979) usa o termo promulgação para descrever a representação de que, ao agir, as pessoas estabelecem e operam estruturas e eventos no contexto da construção de sentido. Ainda, os atores sociais podem decretar limitações sobre o sistema para evitar problemas ou experiências específicos, sendo que o conceito de promulgação se relaciona com as organizações e seu ambiente e gestão estratégica. Nesse caso, a comunicação é fundamental para o processo de organização, uma vez que é o fator comum na construção de sentido compartilhado (WEICK, 1979).

É essa noção de uma cultura comum que Morgan (2002) aponta como contribuição maior de tal visão, a partir da qual a organização pode desenvolver uma gestão autocontrolada, coerente e eficaz. Outro 
aspecto desta visão cultural da empresa demonstra que a organização é baseada em sistemas de valores e significados comuns que, uma vez identificados, podem ser a fonte de inovação e mudança organizacional (MORGAN, 2002). Há de se considerar, todavia, que esta constatação pode levar às tentativas de mecanizar e fixar regras de gestão racionais para um determinado contexto dinâmico, o que seria inconcebível, de acordo com Morgan (2002).

\section{MÉTODO}

A revisão sistemática de literatura foi adotada como estratégia de pesquisa para a construção deste artigo, por meio de uma abordagem qualitativa, com objetivo exploratório e descritivo visou identificar, avaliar e interpretar pesquisas relevantes para um determinado assunto (KITCHENHAM, 2004).

Segundo Maanen (1979) a pesquisa qualitativa compreende um conjunto de diferentes técnicas interpretativas que visam descrever e decodificar os componentes de um sistema complexo por significados. Tem por objetivo traduzir e expressar o sentido dos fenômenos do mundo social; trata-se de reduzir a distância entre indicador e indicado, entre teoria e dados, entre contexto e ação (MAANEN, 1979). Para extrair conclusões das análises, é preciso posicionar os sujeitos em um contexto histórico e social. De acordo com Fonseca (2002), cria-se um informe qualitativo, indo do particular ao geral, somente ao completar esse movimento interpretativo. A pesquisa qualitativa, provavelmente, contribuirá menos à reflexão acadêmica sem essa contextualização.

De acordo com Gibbs (2009), as pesquisas qualitativas apresentam várias peculiaridades tais como: acesso a experiências e ao contexto de determinado problema, hipóteses são desenvolvidas e refinadas durante a pesquisa e forte utilização de notas, manuscritos e de transcrições. Este tipo de pesquisa, por consistir em um conjunto de práticas interpretativas e materiais que tornam o mundo visível, é a atividade investigativa que posiciona o observador no mundo. Neste contexto, Flick (2009) corrobora dizendo que a pesquisa qualitativa envolve um caráter interpretativo e de abordagem naturalística diante do mundo, ou seja, procurando compreender e/ou interpretar os fenômenos em termos dos sentidos que as pessoas lhe atribuem, os pesquisadores estudam as coisas em seus contextos naturais.

O estudo exploratório tem por objetivo possibilitar maior familiaridade com o problema, com vistas a torná-lo mais nítido, auxiliar no desenvolvimento de fatos a serem aferidos, verificar se pesquisas análogas já foram realizadas, apurar problemas do comportamento humano, apontar conceitos ou variáveis e sugerir hipóteses verificáveis (RICHARDSON, 1985; MATTAR, 1999; MALHOTRA, 1993; SAMPIERI; COLLADO; LUCIO, 1998). O aprimoramento de ideias e a descoberta de intuições é o objetivo principal. O pesquisador inicia com uma ideia ou hipótese e faz a exploração com o objetivo de ampliar seu conhecimento em torno de um problema estabelecido, assim o investigador aprofunda seu estudo nas divisas de uma realidade específica (SELLTIZ, 1967; TRIVIÑOS, 1987).

A pesquisa com objetivo descritivo enfoca na descoberta e análise de fenômenos descrevendo-os, classificando-os e interpretando-os. Esta pesquisa analisa fatos e/ou fenômenos, fazendo uma descrição minuciosa da forma como tais fatos e fenômenos se evidenciam. Os fundamentos teóricos da pesquisa descritiva são produzidos depois da análise de dados empíricos, sendo refinados a posteriori, indica-se que utilizam informações obtidas por meio de estudos exploratórios (RUDIO, 1985; DALFOVO; LANA; SILVEIRA, 
2008). A pesquisa descritiva requer do pesquisador um conjunto de informações sobre o que (objeto e objetivo) deseja investigar, esse tipo de estudo objetiva narrar os fatos e fenômenos de determinada realidade (TRIVIÑOS, 1987; OLIVEIRA, 1999).

Para a revisão sistemática da literatura utilizou-se um processo estruturado abrangendo planejamento, execução e análise dos dados pesquisados, pois é uma revisão delineada para responder a uma pergunta específica e que utiliza métodos explícitos e sistemáticos (SILVA et al., 2014; CASTRO, 2006). Em um campo de pesquisa desenvolvido, a revisão sistemática pode proporcionar uma contribuição maior para os pesquisadores que a revisão conceitual, (STAKE, 2011).

No caso das pesquisas na área das ciências sociais, a importância da utilização da revisão sistemática justifica-se pela necessidade de utilização de métodos que possibilitem trazer à tona as contradições, transformando-as em conhecimento (MENDES; FRACOLLI, 2008). Os trabalhos que utilizam este método são considerados trabalhos originais, pois, além de utilizar como fonte dados da literatura sobre determinado tema, são elaborados com rigor metodológico (CASTRO, 2006). Corroborando com o tema Kitchenham (2004) diz que as revisões sistemáticas devem ser realizadas de acordo com uma estratégia de busca predefinida. Para ser avaliada, a estratégia de busca deve permitir a integridade da pesquisa. As etapas seguidas são descritas a seguir.

\section{Estruturação da revisão sistemática}

De acordo com Tranfield, Deyer e Smart (2003), uma avaliação sistemática desenvolve conhecimento confiável a partir de um conjunto de conhecimentos dispersos por meio de uma ampla gama de estudos. A utilização da revisão sistemática permite ao pesquisador mapear e avaliar o território intelectual disponível a fim de tornar o conteúdo encontrado mais consistente e aderente à questão de pesquisa, porém para a realização da investigação acadêmica de um problema de pesquisa específico, torna-se necessário seguir uma estrutura de trabalho rígida (TRANFIELD; DEYER; SMART, 2003).

Para a aplicação da revisão sistemática como forma de pesquisa, foi seguida a estrutura proposta no Quadro 1, o qual compreendeu as etapas de planejamento, análise e execução. 
Quadro 1- Etapas e atividades da revisão sistemática

\begin{tabular}{|c|c|}
\hline Etapas & Atividades da Revisão Sistemática \\
\hline $\begin{array}{l}\text { 1) Planejamento } \\
\text { da pesquisa }\end{array}$ & $\begin{array}{l}\text { Passo 1.1: Definir a questão de pesquisa que irá direcionar a revisão da literatura. A questão de } \\
\text { investigação deve ser clara e concisa; } \\
\text { Passo 1.2: Definir a estratégia de pesquisa, definido quais serão as bases de dados e os períodos } \\
\text { a serem pesquisados; } \\
\text { Passo 1.3: Definir os critérios de inclusão e ou exclusão dos trabalhos a serem analisados. Nesta } \\
\text { etapa é necessário escolher as palavras-chave que sejam adequadas para a seleção dos } \\
\text { trabalhos; } \\
\text { Passo 1.4: Realizar uma seleção preliminar dos trabalhos de acordo com a estratégia de pesquisa } \\
\text { definida no Passo } 1.2 \text { e utilizar os critérios de inclusão e ou exclusão definidos no Passo } 1.3 \text { da } \\
\text { etapa de planejamento. }\end{array}$ \\
\hline $\begin{array}{l}\text { 2) Análise dos } \\
\text { trabalhos } \\
\text { publicados }\end{array}$ & $\begin{array}{l}\text { Passo 2.1: Realizar uma análise profunda nos trabalhos selecionados no Passo 1.4, } \\
\text { considerando obras que apresentam uma relação com a questão de pesquisa. Deve-se definir } \\
\text { categorias para classificação dos trabalhos a fim de organizar a análise e a profundidade dos } \\
\text { trabalhos consultados. }\end{array}$ \\
\hline $\begin{array}{l}\text { 3) Execução da } \\
\text { pesquisa }\end{array}$ & $\begin{array}{l}\text { Passo 3.1: Apresentar os resultados finais da análise, demonstrando os autores e fontes de } \\
\text { consulta que contribuíram para a questão de pesquisa, elaborada no Passo } 1.1 \text { da etapa de } \\
\text { planejamento. }\end{array}$ \\
\hline
\end{tabular}

Fonte: Adaptado de Silva et al., 2014.

Flick (2009) comenta que a definição da questão de pesquisa compreende uma etapa importante do trabalho, pois é necessário esclarecer esta questão por meio de investigação e se familiarizar com a literatura existente sobre ela. De acordo com o passo 1.1 de Silva et al. (2014), a questão norteadora desta revisão busca analisar a evolução dos estudos sobre as organizações vistas como culturas com base nos estudos de Gareth Morgan e sua base teórica do livro "Imagens da Organização", 2002. Esta questão proposta foi realizada de forma peculiar, pois havia a intenção de conhecer qual a evolução dos estudos analisando as temáticas que se referenciaram a Morgan.

Segundo Flick (2009), a qualidade é uma das principais questões na construção do desenho de uma pesquisa padronizada, talvez a mais importante. Nesse contexto, a qualidade está intimamente ligada à padronização e ao controle da situação de pesquisa e às influências que ela sofre (FLICK, 2009). Seguindo os estudos de Silva et al. (2014), o passo 1.2 das atividades da revisão sistemática, para a realização deste trabalho foram efetuadas pesquisas na base de dados Scopus, sendo pesquisados somente "artigos", das Ciências Sociais e Humanas até o ano de 2016. A estratégia de busca deu-se em três etapas, sendo iniciada pela busca das palavras chaves em todos os índices, seguida por títulos, resumos e palavras chaves e, por fim, somente no título (conforme Quadro 02). Utilizou-se como filtro a busca das palavras chaves somente no título dos artigos, entende-se que é onde estão apresentadas as características do estudo, podendo assim identificar a pertinência ou não ao tema estudado (JUNIOR; ENSSLIN; ENSSLIN, 2014).

Silva et al. (2014) afirma que no passo 1.3 deve-se escolher as palavras-chave e analisar os critérios de exclusão e/ou inclusão dos artigos encontrados, por isso após uma pesquisa prévia na literatura estudada, foram escolhidas as seguintes palavras-chave: organizational e culture, com o filtro no título, e Images of Organization com filtro como referências, conforme a Figura 1. 
Figura 1- Estratégias de busca na base de dados Scopus.

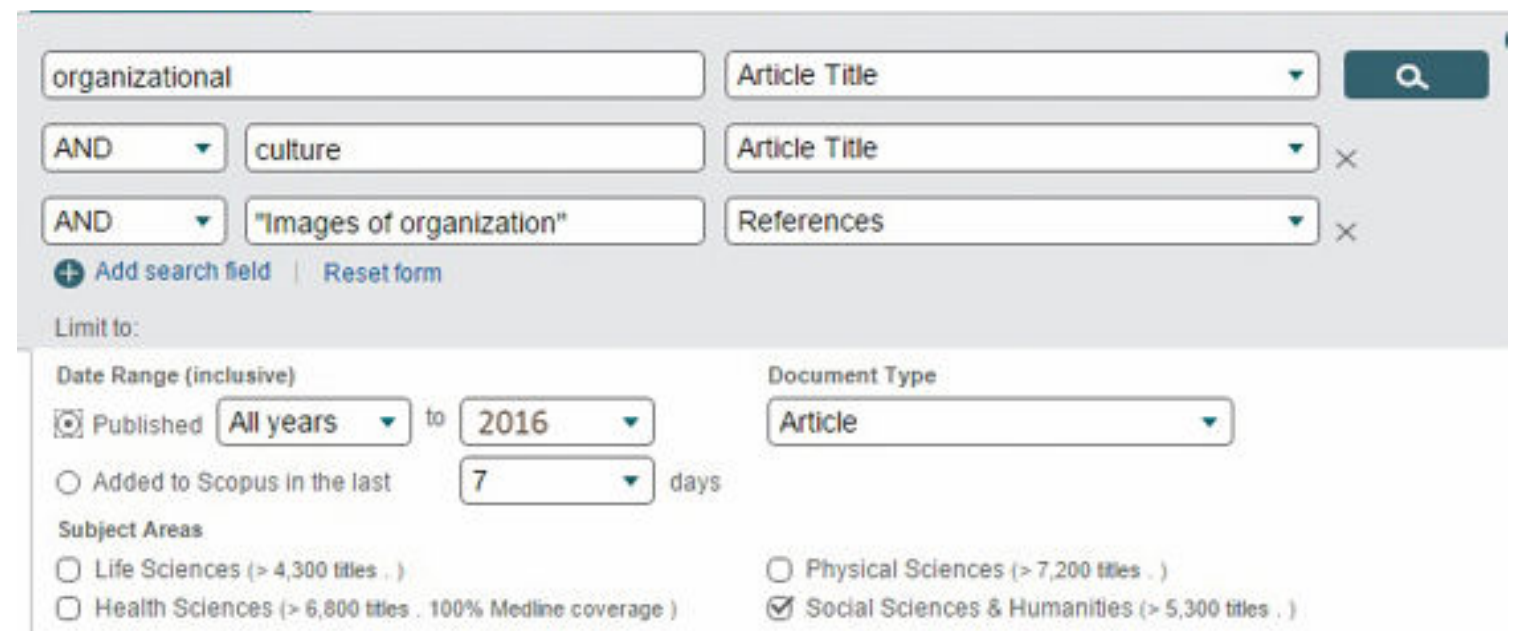

Fonte: elaborado pelos autores

Com a intenção de possibilitar ao leitor a análise dos dados, antes da apresentação das inferências dos autores, os resultados obtidos em cada fase da estratégia de recuperação das fontes são sintetizados no Quadro 2.

Quadro 2 - Frequência de fontes recuperadas por meio da estratégia delineada

\begin{tabular}{|c|c|c|}
\hline \multicolumn{2}{|c|}{ FREQUÊNCIA TOTAL DE FONTES RECUPERADAS MEDIANTE CADA ESTRATÉGIA } \\
\hline Base de Dados & Estratégia - todos os índices & N. Fontes Recuperadas \\
\hline SCOPUS & $\begin{array}{c}\text { Organizational and Culture (as reference "Images of } \\
\text { Organizations") }\end{array}$ & 1,166 \\
\hline Base de Dados & Estratégia - títulos, resumos e palavras chaves & N. Fontes Recuperadas \\
\hline SCOPUS & $\begin{array}{c}\text { Organizational and Culture (as reference "Images of } \\
\text { Organizations") }\end{array}$ & 198 \\
\hline Base de Dados & Estratégia - somente títulos & N. Fontes Recuperadas \\
\hline SCOPUS & $\begin{array}{c}\text { Organizational and Culture (as reference "Images of } \\
\text { Organizations") }\end{array}$ & \\
\hline
\end{tabular}

Fonte: elaborado pelos autores

Para esta análise, utilizaram-se os critérios de inclusão e exclusão dos trabalhos pesquisados, sendo estes compostos somente por artigos de periódicos científicos (não foram acessados trabalhos do tipo livro, imagens, teses, dissertações ou monografias) (SILVA et al., 2014). O pesquisador não deve levar em consideração qualquer juízo de valor em relação ao conteúdo, deve seguir um critério adequado, mantendo critérios claros dos trabalhos que foram analisados (KITCHENHAM, 2004; SILVA, et al., 2014).

Os critérios gerais de exclusão e inclusão são considerados importantes para avaliar a qualidade dos estudos primários (KITCHENHAM, 2004). Após o download dos 55 artigos resultantes da estratégia de busca, adotou-se a divisão dos artigos entre os autores, para a leitura de todos os resumos dos trabalhos que apareceram como resultado da busca na base de dados, com base nas palavras-chave definidas no passo 
1.3 da etapa de planejamento. E, posteriormente, para aprofundamento leu-se o texto na íntegra, desta forma emergiram os critérios de inclusão/exclusão:

i) artigos que não permitiram a visualização/download da versão completa "not open file";

ii) como critério de inclusão buscou-se identificar os artigos que considerassem dois pontos principais, são eles: as organizações como fenômenos culturais e/ou vistas como culturas e; a criação da realidade organizacional a partir deste enfoque.

No próximo passo 1.4, seguindo a sequência do quadro proposto por Silva et al., (2014), foi realizado uma seleção preliminar dos trabalhos de acordo com a estratégia de pesquisa definida no passo 1.2 e utilizado os critérios de inclusão e ou exclusão definidos no passo 1.3 da etapa de planejamento. Por isso, apresentamse no Quadro 3 os sete artigos selecionados seguindo estes critérios.

Quadro 3 - Identificação e descrição das fontes posterior à análise de inclusão e exclusão

\begin{tabular}{|c|c|c|}
\hline Título & Ano & Autores \\
\hline $\begin{array}{l}\text { Do Occupational Groups Vary in Expressed Organizational Culture } \\
\text { Preferences? A Study of Six Occupations in the United States }\end{array}$ & 2004 & Kwantes; Boglarsky \\
\hline Brazilian National Culture, Organizational Culture and Cultural Agreement & 2006 & De Hilal \\
\hline $\begin{array}{c}\text { Perceptions of organizational culture, leadership effectiveness and personal } \\
\text { effectiveness across six countries }\end{array}$ & 2007 & Kwantes; Boglarsky \\
\hline $\begin{array}{c}\text { An evaluation of a new instrument to measure organizational safety culture } \\
\text { values and practices }\end{array}$ & 2007 & $\begin{array}{l}\text { Díaz-Cabrera; Hernandez- } \\
\text { Fernaud; Isla-Díaz }\end{array}$ \\
\hline CEO values, organizational culture and firm outcomes & 2008 & Berson, Oreg; Dvir \\
\hline Culture and organizational learning & 2011 & Cook; Yanow \\
\hline Organizational culture in knowledge creation, creativity and innovation & 2014 & Auernhammer; Hall \\
\hline
\end{tabular}

Fonte: elaborado pelos autores

O principal propósito de uma revisão sistemática é identificar, apresentar e discutir as contribuições mais importantes de uma área particular de um estudo (BECHEIKH; LANDRY; AMARA, 2006). A segunda etapa da revisão sistemática compreende a análise dos trabalhos que resultaram da pesquisa.

A descrição do passo 2.1 diz que o pesquisador deve realizar uma análise aprofundada do conteúdo dos trabalhos selecionados no passo 1.4 da etapa 1, considerando as obras que apresentam uma relação direta com a questão de pesquisa (KITCHENHAM, 2004; SILVA, et al., 2014).

Para verificar a evolução dos estudos sobre as organizações vistas como culturas, durante a análise das publicações, foram identificados os principais aspectos que pudessem responder às questões de pesquisa e, também, foi elaborada uma classificação das principais ideias extraídas dos trabalhos (conforme Quadro 4). Sendo estas propulsoras do estado da arte contidas no referencial e base de sustentação para a criação da metáfora da cultura organizacional (CO) que propusemos ao final deste artigo. 
Quadro 4 - Classificação dos elementos chaves extraídas dos trabalhos

\begin{tabular}{|c|c|c|c|}
\hline Autores & Ano & Titulo & Cultura organizacional \\
\hline $\begin{array}{l}\text { Kwantes; Boglarsky } \\
(2004)\end{array}$ & 2004 & $\begin{array}{l}\text { Do Occupational Groups Vary in Expressed } \\
\text { Organizational Culture Preferences? A Study } \\
\text { of Six Occupations in the United States }\end{array}$ & Gênero - Liderança \\
\hline De Hilal (2006) & 2006 & $\begin{array}{l}\text { Brazilian National Culture, Organizational } \\
\text { Culture and Cultural Agreement }\end{array}$ & Liderança - Subculturas \\
\hline $\begin{array}{l}\text { Kwantes; Boglarsky } \\
(2007)\end{array}$ & 2007 & $\begin{array}{l}\text { Perceptions of organizational culture, } \\
\text { leadership effectiveness and personal } \\
\text { effectiveness across six countries }\end{array}$ & $\begin{array}{l}\text { Liderança - Desempenho } \\
\text { Organizacional }\end{array}$ \\
\hline $\begin{array}{l}\text { Díaz-Cabrera; } \\
\text { Hernandez-Fernaud; } \\
\text { Isla-Díaz (2007) }\end{array}$ & 2007 & $\begin{array}{c}\text { An evaluation of a new instrument to measure } \\
\text { organizational safety culture values and } \\
\text { practices }\end{array}$ & $\begin{array}{c}\text { Estilos de Liderança - Sistemas } \\
\text { de Comunicação - Padrões de } \\
\text { Motivação - Relações Humanas } \\
\text { e Inovação }\end{array}$ \\
\hline $\begin{array}{l}\text { Berson; Oreg; Dvir } \\
(2008)\end{array}$ & 2008 & $\begin{array}{c}\text { CEO values, organizational culture and firm } \\
\text { outcomes }\end{array}$ & $\begin{array}{c}\text { Inovação - Burocracia - } \\
\text { Orientação Favorável (cultura } \\
\text { de apoio) }\end{array}$ \\
\hline Cook; Yanow (2011) & 2011 & Culture and organizational learning & $\begin{array}{l}\text { Liderança - Conhecimento - } \\
\text { Aprendizagem Organizacional }\end{array}$ \\
\hline $\begin{array}{l}\text { Auernhammer; Hall } \\
(2014)\end{array}$ & 2014 & $\begin{array}{l}\text { Organizational culture in knowledge creation, } \\
\text { creativity and innovation }\end{array}$ & $\begin{array}{l}\text { Conhecimento - Criatividade - } \\
\text { Inovação }\end{array}$ \\
\hline
\end{tabular}

Fonte: elaborado pelos autores

Após a leitura em profundidade dos artigos pesquisados (realizada por todos os pesquisadores), foi possivel identificar os elementos-chave que emergem dos estudos. Os termos encontrados foram caracterizados como classificações e relacionam-se com os pilares encontrados nos estudos de Morgan (2002). Assim, podemos destacar a relação entre condições sociais e sociedade organizacional (MORGAN, 2002), onde surgiram os seguintes elementos: conhecimento, criatividade, inovação, aprendizagem organizacional. A ligação entre práticas e processo (MORGAN, 2002), onde temos burocracia e liderança e, a correspondência entre interação e contexto situacional (MORGAN, 2002), que se referem à subcultura, gênero, desempenho organizacional e relações humanas.

A execução da pesquisa compreende a terceira etapa da revisão sistemática, descrita no passo 3.1. A realização da pesquisa através da revisão sistemática tem como uma das suas características sistematizar o conteúdo pesquisado (SILVA et al., 2014). Após a análise dos artigos, e a elaboração do quadro das descrições dos artigos selecionados pela revisão sistemática, realizou-se a avaliação do conteúdo das publicações a fim de atender aos objetivos propostos pela pesquisa. Nas seções a seguir, apresenta-se a descrição e análise dos resultados da revisão sistemática realizada, e então as considerações finais. 


\section{DESCRIÇÃO E ANÁLISE DOS RESULTADOS}

Após a aplicação do método de revisão sistemática para estruturação do trabalho, realizou-se a execução da pesquisa, que compreende a etapa 3 prevista na metodologia empregada no trabalho. Utilizando as palavras-chave selecionadas e após utilizar os critérios de inclusão e exclusão, restaram sete artigos, que serão descritos a seguir.

O último passo metodológico deste estudo foi a realização de uma análise em profundidade dos artigos que têm a cultura organizacional como objeto principal de investigação. Esta busca ocorreu na base internacional Scopus, sendo pesquisados somente "artigos", das Ciências Sociais e Humanas até o ano de 2016. A estratégia de busca deu-se em três etapas, sendo iniciada pela busca das palavras chaves em todos os índices, seguida por títulos, resumos e palavras chaves e, por fim, somente no título (conforme Quadro 02). Nesse sentido, após os critérios de inclusão e exclusão (do passo 1.3 do método da revisão sistemática), sete artigos foram analisados para demonstrar o panorama das publicações sobre a temática do estudo, sendo aprofundados a seguir.

O primeiro artigo é o de Kwantes e Boglarsky (2004), os quais investigaram um grupo de 2614 indivíduos de 138 empresas, entre os anos de 1996 e 2001. Eles estudaram as diferenças na forma como funcionários em seis profissões diferentes (Contabilidade, Sistemas de Informação de Gestão, Marketing, Produção e Secretariado / Clerical) descrevem a cultura organizacional, e a forma que eles sentem que seria mais eficazmente tratada.

Uma das descobertas é que os homens têm preferências pelas culturas organizacionais que são competitivas e enfatizam o esforço e o desempenho mais do que as mulheres. Por outro lado, as mulheres indicaram preferências elevadas para as culturas organizacionais que reforçam a coesão e o apoio. Esses resultados suportam a ideia de que a cultura organizacional não é uma construção homogênea, mas que existem variações de $\mathrm{CO}$, incorporando tanto a integração e perspectivas de diferenciação para compreender e identificar a cultura organizacional.

Outro estudo foi o de Hilal (2006), que realizou sua pesquisa em uma companhia brasileira que conta com 81.500 colaboradores. A empresa tem filiais no exterior, mais especificamente, nas Américas do Norte e Latina, Europa e Ásia. A autora verificou que a complexidade do ambiente interno de organizações com operações internacionais aumenta a probabilidade de que sua cultura tenda a diferenciação, isto é, múltiplos sistemas de significados e, portanto, de práticas, tendem a coexistir simultaneamente. Os diferentes sistemas de significados, ou de diferentes subculturas, geralmente afetam as operações dessas organizações. Grupos com diferentes pontos de vista culturais tendem a interpretar e a responder aos mesmos eventos organizacionais de diferentes maneiras - aceitando, modificando, questionando ou mesmo ignorando as regras e procedimentos que emanam da cultura dominante.

Um dos fatores-chave que diferencia a cultura de um organismo a partir da cultura de outro, e provavelmente o mais importante fator, é a cultura nacional. As premissas básicas, trajes, crenças e valores, bem como os artefatos que caracterizam a cultura de uma organização, são sempre, de alguma forma, abrangidos pela correspondente cultura nacional. É, portanto, impossível estudar a cultura das organizações que operam em uma sociedade, sem estudar a cultura da sociedade. De Hilal (2006) constatou que a análise da cultura organizacional é um fator-chave, a fim de gerir a mudança em uma organização, e, como tal, a sua 
compreensão requer a identificação de valores e práticas, bem como a existência de clusters de acordo cultural e a possibilidade de coexistência de diferentes sistemas de significados.

Os autores Kwantes e Boglarsky (2007) aplicaram uma survey entre os anos de 1996 e 1999 para 3275 respondentes em seis países diferentes. O artigo buscou perceber como a cultura organizacional está relacionada com a eficácia dos líderes e a eficácia pessoal. O projeto utilizava a perspectiva da CO como uma percepção individual de um fenômeno organizacional. Apuraram que os líderes da organização têm a capacidade de impactar na eficácia de uma organização, exercendo controle sobre as variáveis relacionadas com a cultura organizacional. No geral, os resultados desta pesquisa fornecem um forte apoio para a ideia de que CO está relacionada com liderança e eficácia pessoal.

Díaz-Cabrera, Hernandez-Fernaud e Isla-Díaz (2007) realizaram um estudo em cinco empresas de diferentes setores, cujo objetivo principal era avaliar um instrumento para a medição da cultura de segurança centrada em valores e práticas. Verificaram que a organização é vista como uma minissociedade, cujos membros vêm para dividir sistemas de valor e significado sobre segurança, facilitando assim o desenvolvimento de uma identidade organizacional com o compromisso de prevenção de riscos.

Eles propuseram a coexistência de quatro modelos culturais nas organizações. Os resultados indicam duas principais funções discriminantes que combinam diferentes estilos de liderança, sistemas de comunicação e vários padrões de motivação. A segunda função reflete um pequeno grupo de características específicas que indicam uma orientação cultural no sentido de relações humanas e inovação.

Berson, Oreg e Dvir (2008) estudaram a relação entre os valores do CEO (autodireção, segurança e benevolência) e os resultados organizacionais (crescimento nas vendas, eficiência e satisfação) em 139 empresas israelenses de capital aberto. E, entre estas duas perspectivas, está a cultura organizacional (inovação, burocracia e apoio). Os CEOs são os responsáveis pela gestão da CO e de modificá-la de acordo com as necessidades do ambiente, desde que estejam visando os resultados organizacionais. Alinhados à inovação, a burocracia e às culturas de apoio, buscaram os valores pessoais particulares com que essas dimensões de cultura mais estreitamente correspondem, ou seja, autodireção, segurança e benevolência.

Verificaram que as culturas de líderes que valorizam a liberdade e a criatividade tendem a manter uma maior ênfase na inovação como uma característica cultural chave. Por sua vez, estas culturas são passíveis de contribuir aos resultados de desempenho, como o crescimento de vendas da empresa. CEOs que valorizam a estabilidade, a ordem e a previsibilidade são mais propensos a usar as regras e procedimentos rigorosos e formais, como são incorporados em culturas burocráticas. Por sua vez, essas culturas têm uma associação positiva com a eficiência e uma associação negativa com a satisfação do empregado. E, por fim, as organizações de CEOs que valorizam a benevolência tendem a apresentar uma ênfase no apoio e na cooperação entre os funcionários. Tais culturas de apoio são, por sua vez, associadas a uma maior satisfação do empregado. Os CEOs e a cultura de suas organizações tendem a convergir e as dimensões da cultura estão significativamente associadas aos resultados organizacionais, ou seja, isso implica que a eficácia de um certo CEO pode variar em função do contexto ambiental na qual a empresa está inserida.

Cook e Yanow (2011), por meio de uma revisão bibliográfica, propõe uma perspectiva cognitiva sobre a aprendizagem organizacional, com base no conceito de cultura organizacional como complemento deste aprendizado. Os autores tratam as organizações como grupos humanos, portanto dizem que a 
aprendizagem organizacional envolve significados associados à partilhada, e esta aprendizagem é realizada por meio de artefatos culturais. Entende-se como uma atividade da organização, isto é, uma atividade ao nível do grupo, não no nível do indivíduo. A perspectiva cultural explora o significado da aprendizagem organizacional começando pelas observações empíricas de ação do grupo ao invés de confiar em argumentos conceituais sobre semelhanças entre teorias da cognição individual e teorias das organizações.

Cook e Yanow (2011) concluíram que, quando as organizações são vistas como culturas, elas aprendem por meio de atividades, envolvendo artefatos culturais, e o aprendizado, por sua vez, é conhecido por ocasionar aquisições para a empresa, mudanças, ou preservar suas habilidades. Os autores destacam a capacidade dos indivíduos agirem em grupos, que estes grupos, com sua história ou prática conjunta são entendidos como cultura. Tal cultura é constituída de significados intersubjetivos que seus membros expressam em comum, praticam por meio de objetos, linguagem e atos, os quais são portadores de significado e transmitem o conhecimento coletivo ou o know-how de uma organização com o propósito de preservar sua identidade cultural.

O estudo de Auernhammer e Hall (2014) investigou uma empresa alemã de fabricação de automóveis, entre os anos de 2007 a 2011. Por meio de uma abordagem mista, o artigo explorou o conhecimento e a gestão da criatividade relacionados à cultura organizacional. Isto inclui liderança, condições sociais e sua influência nas práticas de criatividade e inovação como interação individual dentro do contexto organizacional. $\mathrm{Na}$ abordagem quantitativa, foi possível verificar que alguns fatores são necessários para nutrir um ambiente propício à criação de conhecimento, criatividade e inovação. A organização deve estar aberta a mudanças, encorajar e valorizar a comunicação livre e ideias novas e/ou incomuns, e motivar seus colaboradores. A existência de líderes que apoiem e promovam essas características, favorece o compartilhamento de valores organizacionais, ao mesmo tempo em que desafiam e capacitam sua equipe a gerar novas ideias para impulsionar a inovação. Em geral, o estudo identificou três estratos de influência: aqueles relacionados com (i) a macroestrutura, como é evidente na cultura da organização; (ii) interações sociais realizadas entre indivíduos; e (iii) processos cognitivos individuais.

Todos os trabalhos supracitados utilizaram como referencial o trabalho original de Morgan, e a partir dessas análises foi possível identificar a relação com a teoria do Morgan e as suas contribuições, sendo apresentados no Quadro 5. 
Quadro 5 - Resumo do resultado e comparação com Morgan

\begin{tabular}{|c|c|c|}
\hline Autores & Contribuição & Relação com a Teoria do Morgan \\
\hline $\begin{array}{l}\text { Kwantes; } \\
\text { Boglarsky (2004) }\end{array}$ & $\begin{array}{l}\text { Os resultados encontrados suportam a } \\
\text { ideia de que a cultura organizacional } \\
\text { não é uma construção homogênea. }\end{array}$ & $\begin{array}{l}\text { As organizações são dependentes de um tipo de } \\
\text { cultura que a caracteriza, ou seja, elas crescem em } \\
\text { um quadro cultural definido. }\end{array}$ \\
\hline De Hilal (2006) & $\begin{array}{l}\text { A análise da cultura organizacional é } \\
\text { essencial para gerir a mudança em uma } \\
\text { organização, o que requer a } \\
\text { identificação de valores, práticas e } \\
\text { diferentes sistemas de significados. }\end{array}$ & $\begin{array}{l}\text { Cultura organizacional, neste contexto, se } \\
\text { fundamenta e reflete os valores e crenças que } \\
\text { caracterizam as diferentes culturas onde estão } \\
\text { inseridas as organizações. }\end{array}$ \\
\hline $\begin{array}{l}\text { Kwantes; } \\
\text { Boglarsky (2007) }\end{array}$ & $\begin{array}{l}\text { A cultura organizacional está } \\
\text { relacionada com a eficácia dos líderes e } \\
\text { a eficácia pessoal. }\end{array}$ & $\begin{array}{l}\text { Organizações são um complexo de pequenos } \\
\text { grupos em interação que têm influência sobre o } \\
\text { comportamento semelhante. }\end{array}$ \\
\hline $\begin{array}{l}\text { Díaz-Cabrera; } \\
\text { Hernandez- } \\
\text { Fernaud; Isla-Díaz } \\
\text { (2007) }\end{array}$ & $\begin{array}{l}\text { Foram encontradas duas principais } \\
\text { funções que combinam diferentes } \\
\text { estilos de liderança, sistemas de } \\
\text { comunicação e vários padrões de } \\
\text { motivação. A segunda função reflete } \\
\text { uma orientação cultural no sentido de } \\
\text { relações humanas e inovação. }\end{array}$ & $\begin{array}{l}\text { Tais grupos imprimem valores organizacionais em } \\
\text { seus membros; recompensam o cumprimento e } \\
\text { punem aqueles que resistem às suas demandas. }\end{array}$ \\
\hline $\begin{array}{l}\text { Berson, } \\
\text { Oreg; } \\
\text { Dvir (2008) }\end{array}$ & $\begin{array}{l}\text { Verificou-se que a cultura de líderes que } \\
\text { valorizam a criatividade, tende a } \\
\text { enfatizar a inovação e, contribuem } \\
\text { também para o melhor desempenho da } \\
\text { organização. }\end{array}$ & $\begin{array}{l}\text { Ao agir, as pessoas estabelecem e operam } \\
\text { estruturas e eventos no contexto da construção de } \\
\text { sentido. Ainda, os atores sociais podem decretar } \\
\text { limitações sobre o sistema para evitar problemas } \\
\text { ou experiências específicos. }\end{array}$ \\
\hline $\begin{array}{l}\text { Cook; } \\
\text { Yanow (2011) }\end{array}$ & $\begin{array}{l}\text { As organizações vistas como culturas } \\
\text { aprendem por meio de atividades, as } \\
\text { quais envolvem artefatos culturais, e o } \\
\text { aprendizado é conhecido por ocasionar } \\
\text { mudanças ou preservar suas } \\
\text { habilidades. }\end{array}$ & $\begin{array}{l}\text { A cultura da empresa é o conjunto de } \\
\text { comportamentos individuais que definem a } \\
\text { identidade de uma organização. O padrão } \\
\text { desempenha um grande papel na motivação dos } \\
\text { empregados ou desinteresse, é em grande parte } \\
\text { influenciado pelo contexto cultural em que a } \\
\text { empresa opera. }\end{array}$ \\
\hline $\begin{array}{l}\text { Auernhammer; } \\
\text { Hall (2014) }\end{array}$ & $\begin{array}{l}\text { O estudo relacionou a cultura } \\
\text { organizacional ao conhecimento e a } \\
\text { gestão da criatividade, o que inclui } \\
\text { liderança, condições sociais e as } \\
\text { influências nas práticas de criatividade e } \\
\text { inovação. }\end{array}$ & $\begin{array}{l}\text { Organizações são um processo em constante } \\
\text { mudança, haja vista que as pessoas estão } \\
\text { conscientes dos relacionamentos, e os membros } \\
\text { de uma organização não podem separar-se como } \\
\text { indivíduos. Assim, o indivíduo como membro da } \\
\text { organização é consciente do significado que } \\
\text { impõem a si próprio, aos outros atores e ao } \\
\text { ambiente. }\end{array}$ \\
\hline
\end{tabular}

Fonte: elaborado pelos autores.

A seguir apresentar-se-ão as principais conclusões extraídas dos trabalhos selecionados. 


\section{CONSIDERAÇÕES FINAIS}

Este trabalho analisou a evolução dos estudos sobre as organizações vistas como culturas, com suporte nos estudos de Morgan (2002) e sua base teórica na obra "A Imagem da Organização", por meio de uma revisão sistemática com artigos publicados na base de dados Scopus. Para a construção do trabalho, utilizou-se no referencial teórico alguns clássicos, como Presthus (1962), Garfinkel (1967; 1988) e Weick (1979), entre outros pesquisadores, uma vez que estes autores foram citados por Morgan (2002) e o auxiliaram na construção de sua metáfora.

O desenvolvimento do trabalho conduz à ideia das organizações como manifestações do contexto social onde estão inseridas. As organizações só podem existir em sociedades onde os membros compartilhem das características de um sistema social, de relações. Diante do exposto, como conclusão, os autores destacam os estilos de liderança como recurso fundamental para a perpetuação da cultura organizacional. Esta cultura serve de suporte para a criação de conhecimento e influencia as práticas de criatividade e inovação quando os indivíduos interagem dentro do contexto organizacional da empresa. Tal constatação abre uma perspectiva de análise das organizações como manifestações autocontroladas, uma vez que a interação dos indivíduos pode ser estimulada, mas não diretamente controlada por um único ator social.

Alguns estudos observados utilizam a perspectiva da cultura organizacional para relacionar liderança à eficácia pessoal, originando um melhor desempenho organizacional. Destacou-se também, a importância da $\mathrm{CO}$ a fim de gerir a mudança em uma organização, ressaltando, novamente, o poder do líder como agente desta transformação. Isso quer dizer que, o líder, no papel de detentor do poder formal dentro das organizações, pode balizar os padrões de relacionamento entre os indivíduos, direcionando as ações para um espectro de possíveis resultados.

Corroborando com os estudos de Morgan (2002), constatou-se que os líderes utilizam rituais, imagens e símbolos para promover a unificação e sustentar os valores da organização. Estes artefatos servem também para promover o aprendizado, o qual será responsável por ocasionar aquisições, mudanças ou preservar suas habilidades. Assim, há a primeira implicação prática da metáfora da cultura para a gestão organizacional, pois, se as organizações são manifestações autogeridas do contexto social onde se inserem, o foco do líder deve se dar no ambiente, a causa, e não no resultado.

Posterior à classificação dos elementos chaves: condições sociais (conhecimento, criatividade, inovação e aprendizagem organizacional), práticas (burocracia e liderança) e interação (subcultura, gênero, desempenho organizacional e relações humanas), obtiveram-se os pilares que sustentam a metáfora da cultura organizacional aqui apresentada:

A cultura organizacional é resultado das práticas organizacionais de interação das condições sociais. A Figura 2 demonstra essas relações. 
Figura 2. Metáfora da cultura organizacional resultante das práticas organizacionais de interação das condições sociais

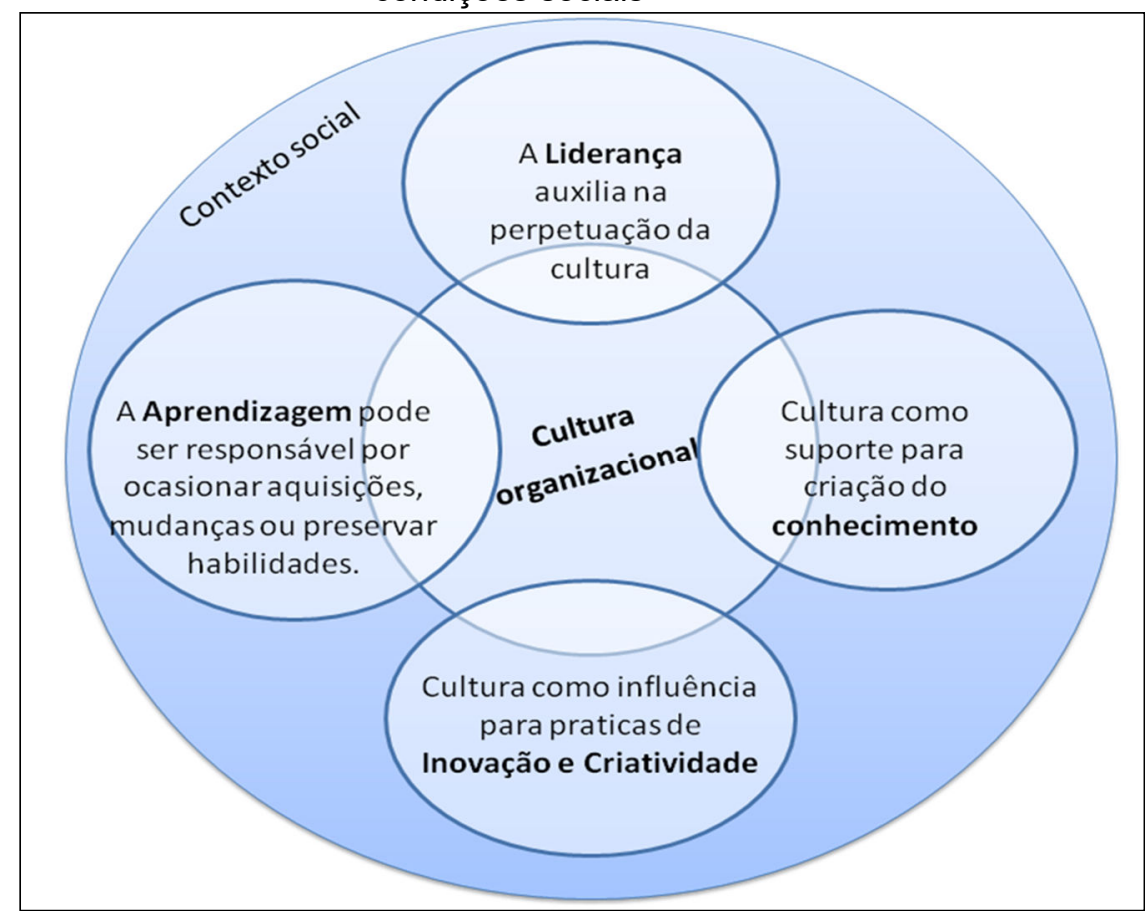

Fonte: Elaborada pelos autores.

Esta proposição de afirmação da metáfora da cultura organizacional encerra os aspectos compreensíveis da metáfora da organização vista como cultura, pois apresenta a equação causa-efeito proposta por Morgan em primeira instância. Quer dizer que a organização, aqui um elemento puramente etéreo, manifestada como uma cultura organizacional vai existir apenas como resultado das interações de um ambiente único. Logo, a sociedade deixa de ser uma fonte, fazendo sentido em si mesma, para ser uma simulação, existindo por meio das relações simbólicas entre os signos. Portanto, as organizações são manifestações não mais da natureza, e sim de uma representação. Seria como dizer, analogamente ao mito da caverna, que vemos não mais as sombras do mundo, senão sombras dos símbolos que representam o mundo.

É importante ressaltar que, este artigo não tem como objetivo desconstruir a metáfora das organizações vistas como culturas de Morgan, e sim, atualizar os achados com estudos similares, buscando uma nova metáfora, metáfora esta da cultura organizacional. As limitações da pesquisa são inerentes a toda e qualquer pesquisa, enfatiza-se aqui, a falta de acesso a todos os artigos remanescentes a estratégia de busca devido ao not open file. Como sugestão para pesquisa futura, acredita-se que a partir desta revisão e da metáfora proposta, pode-se buscar novas pesquisas empíricas para comprovar a metáfora, e verificar se, nas organizações atuais a cultura organizacional é resultado das práticas organizacionais de interação das condições sociais. 


\section{REFERÊNCIAS}

AUERNHAMMER, Jan; HALL, Hazel. Organizational culture in knowledge creation, creativity and innovation: Towards the Freiraum model. Journal of Information Science, v. 40, n. 2, p. 154-166, 2014.

BECHEIKH, Nizar; LANDRY, Rejean; AMARA, Nabil. Lessons from innovation empirical studies in the manufacturing sector: A systematic review of the literature from 1993-2003. Technovation, v. 26, n. 5, p. 644-664, 2006.

BERSON, Yair; OREG, Shaul; DVIR, Taly. CEO values, organizational culture and firm outcomes. Journal of Organizational Behavior, v. 29, n. 5, p. 615-633, 2008.

CASTRO, Aldemar Araujo. Revisão sistemática e meta-análise. Compacta: temas de cardiologia, v. 3, n. 1, p. 5-9, 2001.

COOK, SD Noam; YANOW, Dvora. Culture and organizational learning. Journal of Management Inquiry, v. 20, n. 4, p. 362-379, 2011.

DALFOVO, Michael Samir; LANA, Rogério Adilson; SILVEIRA, Amélia. Métodos quantitativos e qualitativos: um resgate teórico. Revista Interdisciplinar Científica Aplicada, Blumenau, v. 2, n. 4, p. 01-13, 2008.

DE HILAL, Adriana V. Garibaldi. Brazilian National Culture, Organizational Culture and Cultural Agreement Findings from a Multinational Company. International Journal of Cross Cultural Management, v. 6, n. 2, p. 139-167, 2006.

JUNIOR, Emílio Della Bruna; ENSSLIN, Leonardo; ENSSLIN, Sandra Rolim. Seleção e análise de um portfólio de artigos sobre avaliação de desempenho na cadeia de suprimentos. Gepros: Gestão da Produção, Operações e Sistemas, v. 7 , n. 1, p. 113, 2012.

DÍAZ-CABRERA, D.; HERNANDEZ-FERNAUD, E.; ISLA-DÍAZ, R. An evaluation of a new instrument to measure organisational safety culture values and practices. Accident Analysis \& Prevention, v. 39, n. 6, p. 1202-1211, 2007.

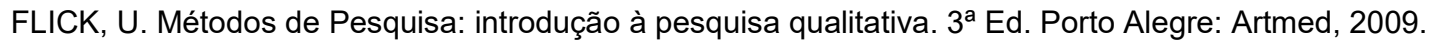

FONSECA, J. J. S. Metodologia da pesquisa científica. Fortaleza: UEC, 2002. Apostila.

GARFINKEL, H. Evidence for locally produced, naturally accountable phenomena of order, logic, reason, meaning, method, etc. in and as of the essential quiddity of immortal ordinary society, (I of IV): An announcement of studies. Sociological Theory, v. 6, n. 1, p. 103-109, 1988.

GARFINKEL, H. Studies in ethnomethodology. Prentice Hall, 1967.

GIBBS, G. Análise de dados qualitativos. Porto Alegre: Artmed, 2009.

KITCHENHAM, Barbara. Procedures for performing systematic reviews. Keele, UK, Keele University, v. 33, n. 2004, p. 126, 2004

KWANTES, Catherine T.; BOGLARSKY, Cheryl A. Do occupational groups vary in expressed organizational culture preferences? A study of six occupations in the United States. International Journal of Cross Cultural Management, v. 4 , n. 3, p. 335-354, 2004.

VAN MAANEN, John. Reclaiming qualitative methods for organizational research: A preface. Administrative science quarterly, v. 24, n. 4, p. 520-526, 1979.

MALHOTRA, N. K. Marketing research: an applied orientation. New Jersey: Prentice-Hall, 1993.

MATTAR, F. N. Pesquisa de marketing: metodologia, planejamento. 5. ed. São Paulo: Atlas, 1999. 1 v.

MENDES, A. L. L.; FRACOLLI, L. Revisão sistemática de literatura e metassíntese qualitativa: considerações sobre sua aplicação na pesquisa em enfermagem. Texto \& Contexto-Enfermagem, v. 17, n. 4, p. 771-778, 2008.

MORGAN, Gareth. Imagens da Organização. Trad. Geni G Goldschmidt. $2^{\mathrm{a}}$ ed. - $4^{\mathrm{a}}$ reimpressão - São Paulo: Atlas, 2002.

OLIVEIRA, S. L. de. Tratado de metodologia científica: projetos de pesquisas, TGI, TCC, monografias, dissertações e teses. 2. ed. São Paulo: Pioneira, 1999. 320 p.

PRESTHUS, R. The organizational society: An analysis and a theory. Vintage Books, 1962.

RICHARDSON, R. et al. Pesquisa social: métodos e técnicas. São Paulo: Atlas, 1985.

RUDIO, F. V. Introdução ao projeto de pesquisa científica. 9. ed. Petrópolis: Vozes, 1985. 121 p.

SAMPIERI, R. H.; COLLADO, C. F.; LUCIO, P. B. Metodología de la investigación. México: McGraw-Hill, 1998.

SELLTIZ, C. Métodos de pesquisa nas relações sociais. São Paulo: Herder, 1967.

SILVA, Rafael M.; SENNA, Eliana T. P.; SENNA, Luiz A. S.; JÚNIOR, Orlando F. Lima. Plataformas Logísticas: uma abordagem sobre as tipologias e características através de uma revisão sistemática. Journal of Transport Literature, 2014.

STAKE, Robert E. Pesquisa qualitativa: estudando como as coisas funcionam. Porto Alegre: Penso, 2011. 
TRANFIELD, David; DENYER, David; SMART, Palminder. Towards a methodology for developing evidence-informed management knowledge by means of systematic review. British journal of management, v. 14, n. 3, p. 207-222, 2003.

TRIVIÑOS, A. N. S. Introdução à pesquisa em ciências sociais: a pesquisa qualitativa em educação. São Paulo: Atlas, 1987.

WEICK, K. E. The social psychology of organizing: Topics in social psychology series. McGraw-Hill Humanities/Social Sciences/Languages, 1979.

WHYTE, William F. Human relations in the restaurant industry. New York: McGraw-Hill, 1948. 